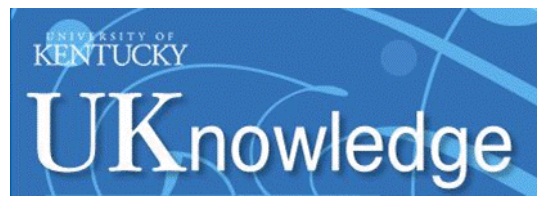

University of Kentucky

UKnowledge

\title{
First Proof of Concept of Sustainable Metabolite Production from High Solids Fermentation of Lignocellulosic Biomass Using a Bacterial Co-Culture and Cycling Flush System
}

Wanying Yao

University of Kentucky

Sue E. Nokes

University of Kentucky, sue.nokes@uky.edu

Follow this and additional works at: https://uknowledge.uky.edu/bae_facpub

Part of the Bacteria Commons, Bioresource and Agricultural Engineering Commons, Biotechnology Commons, and the Oil, Gas, and Energy Commons

Right click to open a feedback form in a new tab to let us know how this document benefits you.

\section{Repository Citation}

Yao, Wanying and Nokes, Sue E., "First Proof of Concept of Sustainable Metabolite Production from High Solids Fermentation of Lignocellulosic Biomass Using a Bacterial Co-Culture and Cycling Flush System" (2014). Biosystems and Agricultural Engineering Faculty Publications. 166.

https://uknowledge.uky.edu/bae_facpub/166

This Article is brought to you for free and open access by the Biosystems and Agricultural Engineering at UKnowledge. It has been accepted for inclusion in Biosystems and Agricultural Engineering Faculty Publications by an authorized administrator of UKnowledge. For more information, please contact UKnowledge@lsv.uky.edu. 
First Proof of Concept of Sustainable Metabolite Production from High Solids Fermentation of Lignocellulosic Biomass Using a Bacterial Co-Culture and Cycling Flush System

Digital Object Identifier (DOI)

https://doi.org/10.1016/j.biortech.2014.08.113

Notes/Citation Information

Published in Bioresource Technology, v. 173, p. 216-223.

(c) 2014. This manuscript version is made available under the CC-BY-NC-ND 4.0 license https://creativecommons.org/licenses/by-nc-nd/4.0/.

The document available for download is the authors' post-peer-review final draft of the article. 


\title{
First Proof of Concept of Sustainable Metabolite Production from High Solids Fermentation of Lignocellulosic Biomass using a Bacterial Co-culture and Cycling Flush System
}

\author{
Wanying $\mathrm{Yao}^{1 *}$, Sue E Nokes ${ }^{1}$ \\ ${ }^{1}$ Department of Biosystems and Agricultural Engineering, University of Kentucky \\ C.E. Barnhart Building, Lexington, KY, 40546
}

Phone: 859.218.4321

Fax: 859.257.5671

Email: julia.yao@uky.edu

\begin{abstract}
To improve the lignocellulosic conversion for $A B E$ in high solids fermentation, this study explored the feasibility of cycling the process repeatedly through the cellulolytic or/and solventogenic phases via intermittent flushing of the fermentation media. Five different flushing strategies (varying medium ingredients, inoculum supplement and cycling through phases) were investigated. Flushing regularly throughout the cellulolytic phase is necessary because re-incubation at $65^{\circ} \mathrm{C}$ significantly improved glucose availability by at least 6 -fold. The solvents accumulation was increased 4-fold using corn stover (3-fold using miscanthus) over that produced by flushing only through the solventogenic phase. In addition, the cycling process was simplified by re-incubating the flushed cellulolytic phase with no re-inoculation because the initial inoculum of Clostridium thermocellum remained viable throughout sequential co-culture. This study served as the first proof of the cycling flush system applied in co-cultural SSC and the knowledge gained can be used to design a farm-scale flushing system.
\end{abstract}


Key words: Periodical flush, Solid substrate cultivation, ABE fermentation, Bacterial co culture cellulolytic and solventogenic phase

\section{Introduction}

The global energy crisis has spurred interest in producing alternative biofuels from clean, renewable feedstocks via biological processes. Lignocellulose is recognized as a promising feedstock for use in biofuel fermentation due to its abundance and renewability, provided that the lignin recalcitrance can be destructed and cellulose components can be utilized efficiently (Kumar et al., 2009). Butanol, used as a biofuel, is currently a favored alternative to ethanol (Nigam \& Singh, 2011; Qureshi \& Blaschek, 2001). Butanol can be produced via acetonebutanol-ethanol ( $\mathrm{ABE}$ ) fermentation by anaerobically cultivating Clostridium strains (Clark et al., 2012). Since butanol-producing bacteria do not have the ability to catabolize complex lignocellulosic feedstocks, lignin removal or modification followed by cellulose hydrolysis is required prior to butanol fermentation. Our previous study explored a biological pretreatment followed by a sequential co-culture of $C$. thermocellum ATCC 27405 and C. beijerinckii ATCC 51743 to ferment ABE solvents from lignocellulosic substrate in batch solid substrate cultivation (SSC) (Yao \& Nokes, 2014). Fungal pretreatment of corn stover using SSC of Phanerochaete. chrysosporium ATCC MYA-4764 (P. chrysosporium) was investigated as a method to preferentially degrade the lignin. Thereafter, $C$. thermocellum was directly inoculated onto the pretreated biomass to enzymatically convert cellulose into reducing sugars, followed by solvent production initiated by introducing C. beijerinckii. C. thermocellum in SSC on fungal pretreated biomass degraded the substrate into a significantly higher yield of glucose $(19-20 \mathrm{mg} / \mathrm{g}$ biomass) than cultures grown on non-pretreated biomass and consequently significantly higher yields of butanol ( $3 \mathrm{mg} / \mathrm{g}$ biomass) were generated by fermenting fungal pretreated biomass compared to the non-pretreated biomass ( $0.5 \mathrm{mg} / \mathrm{g}$ biomass). However, the batch SSC-ABE process still suffered from low yield of acids and solvents even using pretreated biomass. The batch SSC-ABE experienced high initial production rates for all fermentation products, but could 
not sustain these rates. This decrease in rate, and consequently yield, is undesirable as it offsets the advantages of working at high solids levels.

Several mechanisms behind the decreasing conversion in SSC or high solids substrate (high SS), such as osmotic stress, mass transfer limitations and product inhibition, have been proposed and investigated. Bacteria grown in SSC experience a reduced liquid phase and in addition the substrate is exceptionally hypotonic. A shell of hydration forms around the solid particles and the bacteria grow in this water layer. This shell of hydration may experience high concentrations of metabolites, which likely desiccate the bacterial cells by osmosis thus resulting in a decreased final yield and a slowing rate of conversion as the fermentation progresses (Dharmagadda et al., 2010) . In addition, whatever extracellular enzymes that are available experience decreased enzyme activity due to the low availability of water(Gervais \& Molin, 2003; Todd, 1972).

When Clostridium thermocellum bacteria are grown in substrate-excess conditions, growth can be inhibited by the accumulation of fermentation products, either through enzymatic feedback inhibition or metabolic inhibition from high osmotic stress. Termination of growth due to enzymatic feedback inhibition, has been reported; Johnson et al. (1982) saw a 35\% inhibition of C. thermocellum cellulase activity at $60 \mathrm{~g} / \mathrm{L}$ of glucose (Johnson et al., 1982). However, product inhibition by glucose and cellobiose as enzymatic feedback inhibition at high solids loading has not fully accounted for the decreasing conversion. In previously established batch SSC-ABE processes, the level of glucose generated $(4-5 \mathrm{~g} / \mathrm{L})$ by $C$. thermocellum is far below the reported critical levels when the inhibition occurred (Yao \& Nokes, 2014).

Another type of inhibition is caused by hydrolysis sugars released from cellulose and hemicellulose present in SSC. The presence of water soluble sugars (glucose, xylose, etc.) acts to draw water away from insoluble substrate surfaces and could significantly reduce water activity near insoluble substrate surfaces (Selig et al., 2012). The lower water activity may in turn act to reduce the effectiveness of some enzyme systems, specifically enzyme adsorption at these substrate surfaces. Kristensen et al. (2009) found that the amount of adsorbed cellulases 
dramatically dropped at increasing solids substrate concentrations, with only approximately $17 \%$ of the added enzyme adsorbed at $30 \%$ solids filter paper as compared at $70 \%$ adsorbed at low solids. The drop in cellulose adsorption correlated to a decrease in cellulose conversion from $63 \%$ to $38 \%$. Thus the inhibition of cellulase adsorption may be responsible for at least a portion of the decrease in yield in SSC.

In addition to sugars, acids generated by $C$. thermocellum and C. beijerinckii will also exacerbate the already unfavorable osmotic conditions of SSC by prohibiting the cells to maintain isotonic intracellular conditions. This combination (fermentation acids and low water content) has been applied throughout history to prevent microbial growth in food (e.g. cheese, fermented sausage)(Dharmagadda et al., 2010).

One advantage of using a SSC is that the products are produced at a higher concentration than in liquid fermentation. However, these inhibitory issues mentioned above may occur in the SSC process, particularly in the batch mode and do not allow for continuous product accumulation. To address this challenge, this study aims to modify the batch SSC-ABE fermentation developed in our previous study into a periodically flushed process during the cellulolytic or/and solventogenic phases. Our hypothesis is that intermittent flushing with fresh media will provide essential nutrients to the microorganisms while decreasing the osmotic stress and removing the fermentation acids, promoting cell metabolism and growth and thus achieving a higher extent of lignocellulosic biomass conversion. The study investigated five different flushing strategies by varying medium ingredients, re- inoculations after flushing, and the timing of the flushing relative to the fermentation phases. These processing variables were evaluated by quantifying the fermentability of lignocellulose by a bacterial co-culture of $C$. thermocellum and $C$. beijerinckii. Fermentability was quantified by the total amount of carbohydrates released, and acids and solvents produced.

\section{Materials and Methods}




\subsection{Strain cultivation and inoculum preparation}

The white-rot basidiomycete, P. chrysosporium strain (ATCC MYA-4764) was obtained from the American Type Culture Collection (ATCC, Rockville, MD) and maintained as a frozen culture $\left(-80^{\circ} \mathrm{C}\right)$ in $30 \%$ glycerol. Propagation of the organism for SSC was performed as described by Shi et al. (Shi et al., 2009). Spore suspensions were prepared by washing the slant with $10 \mathrm{~cm}^{3}$ of sterilized sodium acetate buffer $(50 \mathrm{mM}, \mathrm{pH} 4.5)$. The final spore inoculum concentration was $5 \times 10^{6}$ spores $/ \mathrm{ml}$, determined using a hemocytometer.

C. thermocellum ATCC 27405 was obtained from ATCC and grown in basal medium that contained (per L) (Dharmagadda et al., 2010): 1530 mg Na $2 \mathrm{HPO}_{4}, 1500$ mg KH $\mathrm{PO}_{4}, 500 \mathrm{mg}$ $\mathrm{NH}_{4} \mathrm{Cl}, 500 \mathrm{mg}\left(\mathrm{NH}_{4}\right)_{2} \mathrm{SO}_{4}, 90 \mathrm{mg} \mathrm{MgCl} \cdot 6 \mathrm{H}_{2} \mathrm{O}, 30 \mathrm{mg} \mathrm{CaCl}$, $4000 \mathrm{mg}$ yeast extract, $10 \mathrm{~cm}^{3}$ standard vitamins (Cotta \& Russell, 1982), $5 \mathrm{ml}$ modified metals (Cotta \& Russell, 1982), $500 \mathrm{mg}$ cysteine hydrochloride, $1 \mathrm{ml}$ resazurin, and $4000 \mathrm{mg}$ sodium carbonate. The medium $\mathrm{pH}$ was adjusted to 6.7 with $\mathrm{NaOH}$ and maintained under a $100 \%$ carbon dioxide atmosphere by sparging with $\mathrm{CO}_{2}$ followed by sealing the container. For seed culture preparation, a bacterial culture from a $-80^{\circ} \mathrm{C}$ stock was grown for $24 \mathrm{~h}$ in Balch tubes at $60^{\circ} \mathrm{C}$ containing $10 \mathrm{ml}$ of basal medium supplemented with $4 \mathrm{~g}$ per liter cellobiose. This initial culture was then used to inoculate $80 \mathrm{ml}$ of cellobiose-containing medium (4 g/L). After $15 \mathrm{~h}$ of growth, this secondary culture was diluted with fresh basal media (without cellobiose) to prepare the standard inoculum stock (final optical density of $0.143 \mathrm{OD}_{600} ; \sim 0.07 \mathrm{~g}$ dry cells/l) for use in flushed solidsubstrate cultivation (FSSC).

C. beijerinckii ATCC 824 purchased from ATCC was also used in this study. Laboratory stocks of C. beijerinckii ATCC 824 were routinely maintained as spore suspensions in sterile doubledistilled water at $4{ }^{\circ} \mathrm{C}$. For seed culture preparation, stock cultures were heat-shocked at $80{ }^{\circ} \mathrm{C}$ for $10 \mathrm{~min}$, and transferred anaerobically into Reinforced Clostridial medium (RCM, Difco Laboratories, Detroit, Mich.) at $35^{\circ} \mathrm{C}$ for $24 \mathrm{~h}$. 


\subsection{Biomass composition}

The corn stover and miscanthus used in this study were harvested using a rotary disc mower at $10 \mathrm{~cm}$ above the ground from the University of Kentucky North Farm in 2011, windrowed and baled. Biomass samples consisted of the whole plant above ground (including stems and leaves), however grain had been previously removed from the corn stover. The biomass was stored in small square bales with $w_{\mathrm{H} 2 \mathrm{O}}<15 \%$ for 9 months. The bales were ground to $5 \mathrm{~mm}$, thoroughly mixing the plant tissue. Samples were air-dried and stored at room temperature.

\subsection{Flushed solid-substrate culture (FSSC)}

FSSC was carried out in $2.5 \mathrm{~cm}$ I.D. and $10 \mathrm{~cm}$ length glass columns fitted with porous polyethylene discs at the bottom (20 $\mu$ m-pores) which allowed media to flow through yet retained the solid substrate. The top and bottom of the columns had polypropylene Luer-Lock fittings. The columns were anaerobically loaded with $5 \mathrm{~g}$ corn stover. In SSC, the pretreatment of $5 \mathrm{~g}$ biomass by $P$. chrysosporium (50 ul of spore culture) was conducted in the glass column at $35{ }^{\circ} \mathrm{C}$. The moisture content was controlled at $70 \%$ (wet basis). Prior to the inoculation of $C$. thermocellum, the column with fungal pretreated biomass was flushed with $\mathrm{CO}_{2}$ for 20 minutes. Ten $\mathrm{ml}$ of $C$. thermocellum standard inoculum of was injected into the glass column through the Luer-Lock fittings with a syringe resulting in an initial inoculum of $0.156 \mathrm{mg}$ dry cells/g substrate. The $\mathrm{CO}_{2}$, along with the gas generated from $\mathrm{C}$. thermocellum during metabolism maintained the anaerobic condition for the mono and co-culture. In our study, the incubation period of $C$. thermocellum was standardized to $48 \mathrm{~h}$ based on an optimization study (data not shown). After a 2-day cultivation of $C$. thermocellum at $65^{\circ} \mathrm{C}$, an inoculum of $1 \mathrm{ml} \mathrm{C}$. beijerinckii at exponential phase was injected into the test tube through the rubber stopper. The sequential co-culture was then incubated at $35{ }^{\circ} \mathrm{C}$ for 2 days. Repeated flushing was initiated at the end of the first sequential co-culture.

The flushing strategies to be investigated were listed in Table 1. The shaded cells indicate during which phase the flushing occurred. The flush cycling was conducted either through the solventogenic phase or through the cellulolytic phase and the solventogenic phase. In the cycling throughout the solventogenic phase, the lignocellulosic substrate was subjected to 
three treatments using three different solutions with which to conduct the flushing: 1) $10 \mathrm{ml}$ of T medium which contained salts, nitrogen and vitamins every 2 days to repeat solventogenic phase at $35^{\circ} \mathrm{C}$ (Treatment 1) ; 2) $10 \mathrm{ml}$ of T medium together with glucose (Treatment 2); 3) 10 $\mathrm{ml}$ of $\mathrm{T}$ medium together with additional C. beijerinckii cells (Treatment 3). The $C$. thermocellum and $C$. beijerinckii were retained as co cultures throughout the solventogenic phase at $35^{\circ} \mathrm{C}$ to metabolize the lignocellulosic substrate (corn stover or miscanthus). In cycling throughout the cellulolytic phase followed by the solventogenic phase, the column was re-incubated at $65{ }^{\circ} \mathrm{C}$ after being flushed with T medium plus the inoculum of $C$. thermocellum (Treatment 4) or with T medium only (Treatment 5). In all treatments, the flushed aqueous solution was collected at the end of the culture phase, centrifuged $\left(5000 \times \mathrm{g}, 10 \mathrm{~min}, 4^{\circ} \mathrm{C}\right)$ and aliquots were stored at $-20{ }^{\circ} \mathrm{C}$ for carbohydrate and end-product analysis.

\subsection{Analysis of co-culture's metabolite production}

The products in the supernatant (lactic acid, acetic acid, butyric acid, ethanol, butanol and acetone) of the fermentation samples were quantified by high-performance liquid chromatography (HPLC) using a Dionex UltiMate 3000 system (Dionex Corporation, Sunnyvale, California). A $300 \times 7.8 \mathrm{~mm}$ Aminex $87 \mathrm{H}$ column was maintained at $20^{\circ} \mathrm{C}$ with a micro-guard cationic $\mathrm{H}$ cartridge at room temperature. The eluent was $5 \mathrm{mM} \mathrm{H}_{2} \mathrm{SO}_{4}$ at a flow rate $0.4 \mathrm{ml}$ $\mathrm{min}^{-1}$. The metabolites were detected using shodex 101 refractive index detector. 
Table 1: Design of Experiment for Fermentation Treatments. The shaded fermentation phases are the ones that were repeated with flushing and the text details additions to the fermentation during each flushing cycle of that phase.

\begin{tabular}{|c|c|c|c|c|c|}
\hline \multicolumn{2}{|c|}{ Flushing strategy } & \multirow{2}{*}{$\begin{array}{c}\text { Fungal } \\
\text { Pretreatment } \\
\text { Standard }\end{array}$} & \multirow{2}{*}{$\begin{array}{l}\text { Substrate } \\
\text { Corn stover }\end{array}$} & \multirow{2}{*}{$\begin{array}{l}\text { Cellulolytic Phase (C. } \\
\text { thermocellum) } \\
\text { Standard }^{+}-1 \text { time }\end{array}$} & \multirow{2}{*}{$\begin{array}{l}\text { Solventogenic Phase (C. beijerinckii) } \\
10 \mathrm{ml} \mathrm{T} \text { medium each cycle }\end{array}$} \\
\hline Treatment 1 & $\mathrm{a}$ & & & & \\
\hline & $b$ & Standard & Miscanthus & Standard - 1 time & $10 \mathrm{ml}$ T medium each cycle \\
\hline \multirow[t]{2}{*}{ Treatment 2} & $\mathrm{a}$ & Standard & Corn Stover & Standard - 1 time & $\begin{array}{l}10 \mathrm{ml} \mathrm{T} \text { medium with } 20 \mathrm{~g} / \mathrm{L} \text { glucose } \\
\text { each cycle }\end{array}$ \\
\hline & $b$ & Standard & Miscanthus & Standard - 1 time & $\begin{array}{l}10 \mathrm{ml} \mathrm{T} \text { medium with } 20 \mathrm{~g} / \mathrm{L} \text { glucose } \\
\text { each cycle }\end{array}$ \\
\hline \multirow{2}{*}{$\begin{array}{l}\text { Treatment } 3 \\
\text { (Data not } \\
\text { shown) }\end{array}$} & $a$ & Standard & Corn Stover & Standard - 1 time & $\begin{array}{l}10 \mathrm{ml} \text { T medium; reinoculate } C . \\
\text { beijerinckii each cycle }\end{array}$ \\
\hline & $b$ & Standard & Miscanthus & Standard - 1 time & $\begin{array}{l}10 \mathrm{ml} \text { T medium; reincoluclate } C \text {. } \\
\text { beijerinckii each cycle }\end{array}$ \\
\hline \multirow[t]{2}{*}{ Treatment 4} & $a$ & Standard & Corn Stover & $\begin{array}{l}10 \text { ml T medium; } \\
\text { reinoculate } C \text {. } \\
\text { thermocellum each cycle }\end{array}$ & $\begin{array}{l}0.5-1 \mathrm{ml} \mathrm{T} \text { medium; reinoculate } C \text {. } \\
\text { beijerinckii each cycle }\end{array}$ \\
\hline & $b$ & Standard & Miscanthus & $\begin{array}{l}10 \text { ml T medium; } \\
\text { reinoculate } C \text {. } \\
\text { thermocellum; each } \\
\text { cycle }\end{array}$ & $\begin{array}{l}0.5-1 \mathrm{ml} \text { T medium; reinoculate } C \text {. } \\
\text { beijerinckii each cycle }\end{array}$ \\
\hline \multirow[t]{2}{*}{ Treatment 5} & $a$ & Standard & Corn stover & $\begin{array}{l}10 \mathrm{ml} \text { T medium each } \\
\text { cycle }\end{array}$ & $\begin{array}{l}0.5-1 \mathrm{ml} \text { T medium; reinoculate } C \text {. } \\
\text { beijerinckii each cycle }\end{array}$ \\
\hline & $b$ & Standard & Miscanthus & $\begin{array}{l}10 \mathrm{ml} \text { T medium each } \\
\text { cycle }\end{array}$ & $\begin{array}{l}0.5-1 \mathrm{ml} \mathrm{T} \text { medium, reinoculate } C \text {. } \\
\text { beijerinckii each cycle }\end{array}$ \\
\hline
\end{tabular}

+ Standard cellulolytic phase: 1 ) an initial inoculum of $0.156 \mathrm{mg}$ dry cells/g substrate 2 ) incubation at $65{ }^{\circ} \mathrm{C}$ for $48 \mathrm{~h}$ 


\section{Results and Discussion}

\subsection{Treatment 1\&2- Cycling through solventogenic phase without or with glucose supplement}

Figure 1a show that approximately $11.6 \mathrm{mg}$ acids/g substrate and $2.3 \mathrm{mg}$ solvents/g substrate were recovered after the first replacement of the corn stover fermentation fluid. Figure $1 \mathrm{~b}$ shows that the cultivation using miscanthus as the substrate accumulated approximately $11 \mathrm{mg}$ solvents/g biomass and $1 \mathrm{mg}$ acids/g biomass after the first fermentation fluid replacement. A subsequent reduction in acids (lactic acid, acetic acid and butyric acid) and solvents (butanol, ethanol and acetone) produced within each cycle was observed (Figures 1a and b). Accumulated acids totaling 39-43 mg total acids/g dried substrate and accumulated solvents totaling 4.8-6 mg total solvents/g dried substrate were obtained after 7 repeated flushes using corn stover or miscanthus respectively under treatment 1 (Table 1 - Treatment 1). The decrease in metabolites produced per cycle, flushing every 48 hours during the solventogenic phase is likely due to limited glucose available in the column reactor. Less than $0.7 \mathrm{~g} / \mathrm{L}(3 \mathrm{mg} / \mathrm{g}$ biomass) of glucose was measured in soluble form throughout flushing process (Figure 1).

Figure 2 presents the metabolites and solubilized glucose when the column reactor was flushed with T medium and glucose during the solventogenic phase (to supplement the available glucose, testing the hyposthesis that the metabolite reduction per cycle seen in Figure 1 was due to insufficient glucose availability to the $C$. beijerinckii). The yields of total acid and total solvents were on the order of 5 6-fold and 9 10-fold higher than without supplemental glucose after the completion of 7 flush cycles using corn stover or miscanthus respectively (Table 1 Treatment 2). Sufficient glucose supplementation throughout the co -culture process enabled increases in metabolite production each cycle (Figure 2) and therefore an increase in the accumulated amount of target metabolites. The cellulosome from $C$. thermocellum must have retained some cellulolytic activity at $35^{\circ} \mathrm{C}$ to hydrolyze the cellulose into glucose which was consumed by $C$. beijerinckii as a substrate for solventogenesis, because $C$. beijerinckii is not known to have cellulolytic activity. However, the cellulosome of $C$. thermocellum did not release sufficient glucose for $C$. beijerinckii to produce metabolites to its full potential during the repeated cycles of solventogenesis at $35^{\circ} \mathrm{C}$ when no glucose was supplemented. 


\section{2 -Treatment 3 - Cycling through solventogenesis with C. beijerinckii re-inoculation}

In Treatment 3a using corn stover, re-inoculation of $C$. beijerinckii during flushing resulted in the total production of $7.5 \mathrm{mg} / \mathrm{g}$ of total solvents which was 1.3 -fold higher than those from treatment $1 \mathrm{a}$ with no re-inoculation of $C$. beijerinckii throughout the flushing cycles (Table 2a). In treatment $3 \mathrm{~b}$ using miscanthus, re-inoculation of $C$. beijerinckii cells corresponded to similar amount of target acids and solvents than those from treatment $1 \mathrm{~b}$ (Table $2 \mathrm{~b}$ ). The results indicate that the lower amount of metabolites seen from Treatment 1 was due to limited access to glucose rather than insufficient $C$. beijerinckii cell mass during the fermentation.

One of the purposes for testing the re-inoculation of $C$. beijerinckii cells after each flush cycle was to increase $C$. beijerinckii cell mass, so that it could potentially outcompete other microorganisms which may contaminate a sterile fermentation. Chen (2013) claimed that the inoculum of Clostridium saccharoperbutylacetonicum N1-4 (ATCC 27021) at a dose higher than $2.2 \mathrm{~g}$ dried cell mass/Lensured a reproducible butanol production even using non-sterile pretreated biomass. That is to say, when the inoculum becomes dominant in the fermentation system, ABE production was not detrimentally influenced by microbial contamination. In Treatments 1 and 2 where no re-inoculation was employed, the collected effluent after each cycle was checked under a microscope and no contamination was found throughout all the cycles.

In Treatment 3, another purpose for re-inoculaing C. beijerinckii was to avoid possible cell degeneration with time. As the solventogenic clostridia cells undergo metabolic shifts between acidogenesis and solventogenesis, the column reactor with re-inoculation of $C$. beijerinckii would be composed of a mixture of actively dividing cells (acidogenic), non-dividing cells (solventogenic), sporulated cells, and dead cells. These diverse cell stages seem appropriate in order to avoid cell degeneration seen in solventogenic cultures that do not receive new cells. In Treatment 2, the concentration of total metabolites produced per flush demonstrated no obvious strain degeneration during at least 7 repeated cycles when no additional inoculum was employed. The increasing rate of accumulation of metabolites after each flush cycle in Treatment 2 indicated that our initial inoculation of $C$. beijerinckii ( $1.5 \mathrm{~g} / \mathrm{L}$ ) was sufficient to 
maintain the process if fed sufficient glucose. Therefore, it is not necessary to re-inoculate $C$. beijerinckii after each flush when the solventogenic phase is repeated in time.

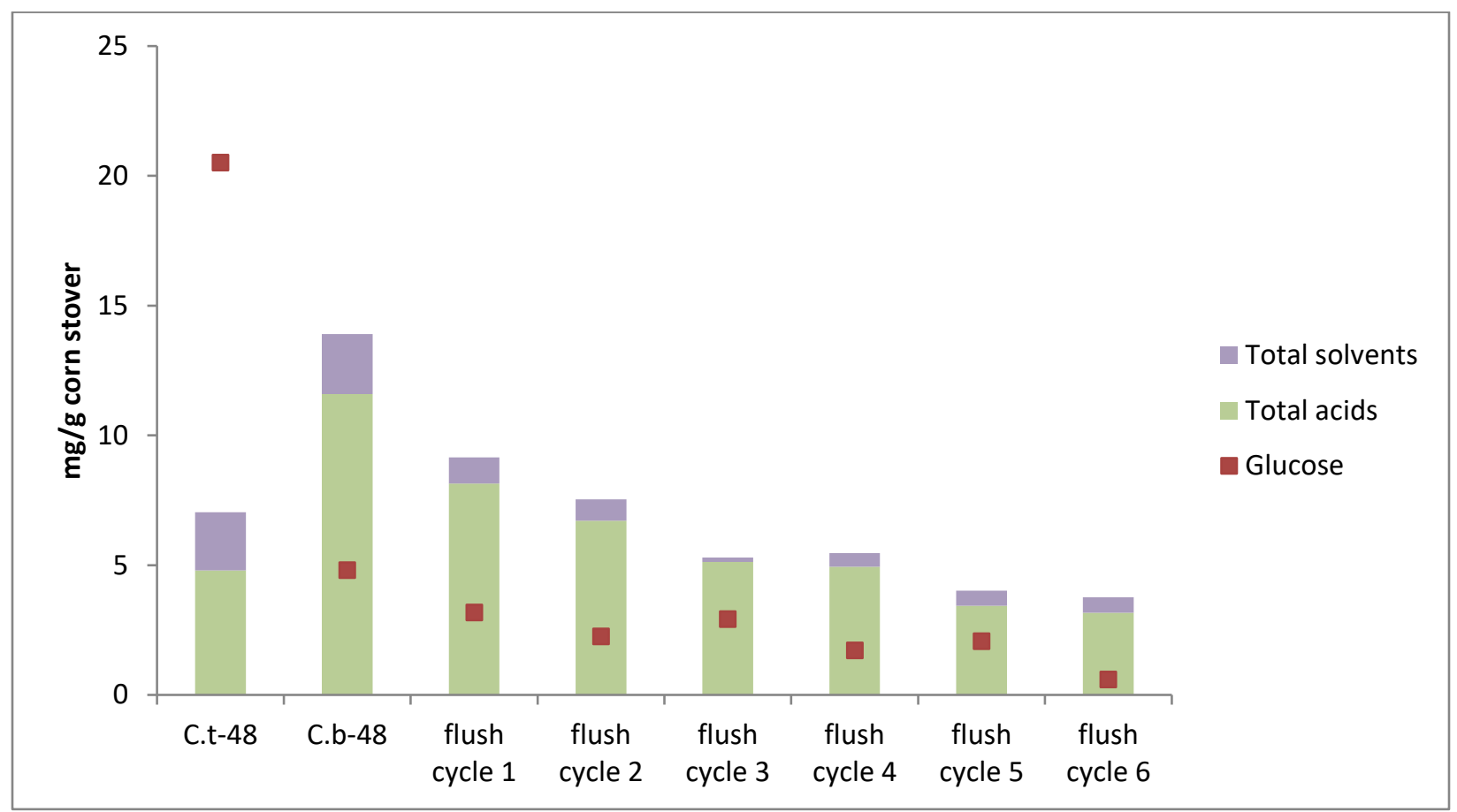

Figure 1a. Cycling through solventogenic phase by repeated flush with T medium using corn stover (refer to Table 1-Treatment 1a).

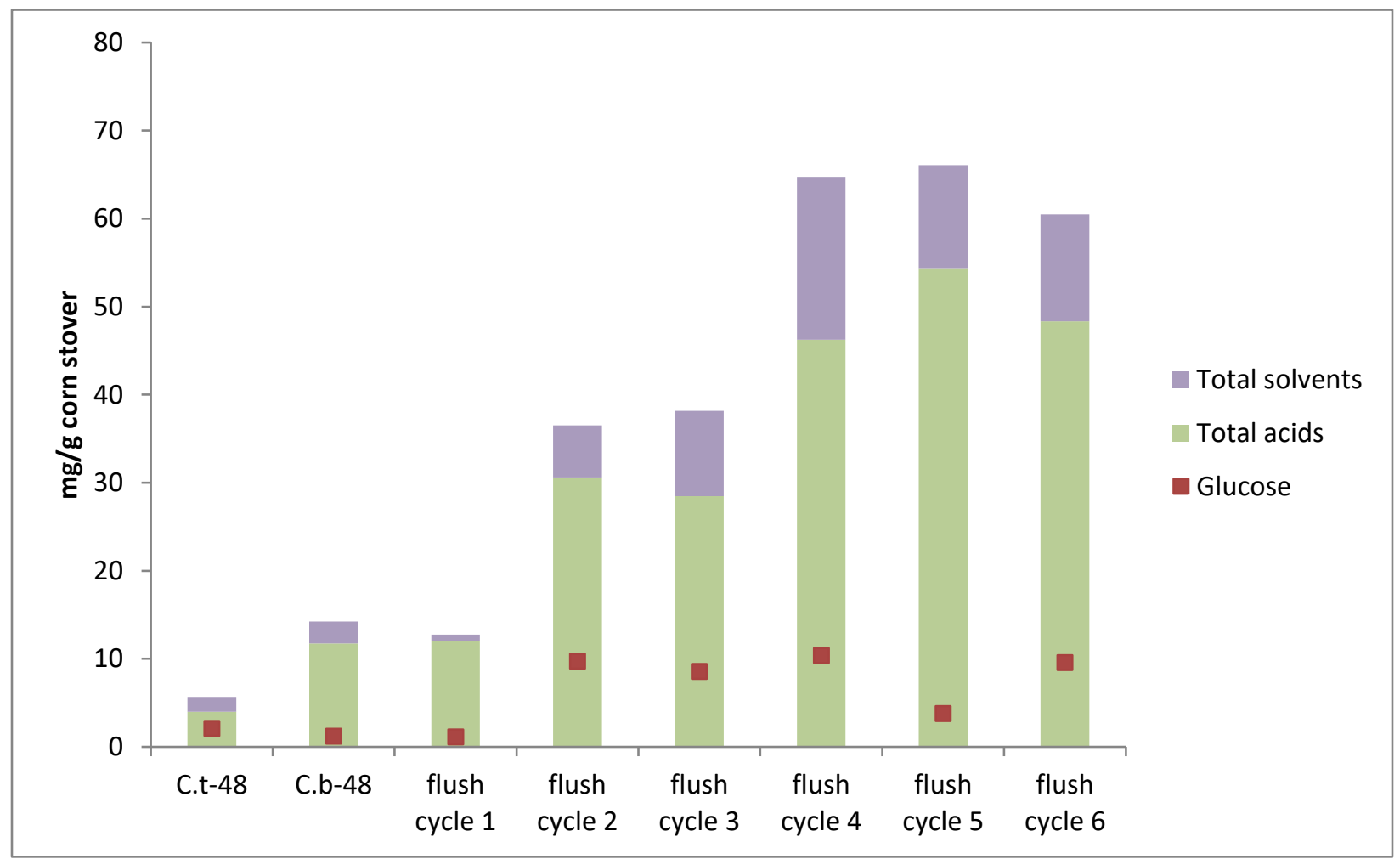


Figure 2a. Cycling through solventogenic phase by repeated flush with T medium and glucose using corn stover (refer to Table 1-Treatment 2a).

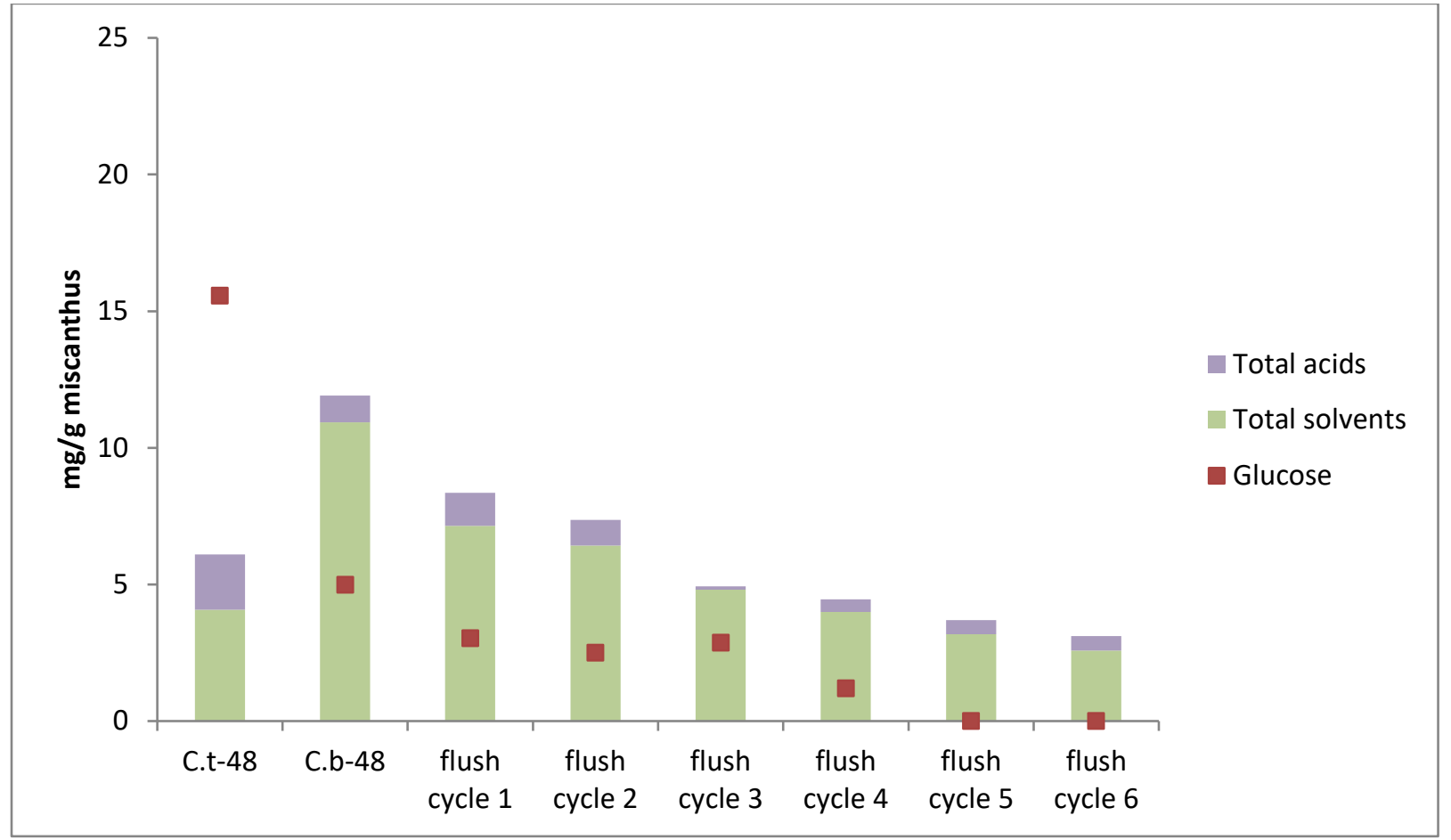

Figure $1 \mathrm{~b}$ Cycling through solventogenic phase by repeated flush with T medium using miscanthus (refer to Table 1-Treatment $1 b$ )

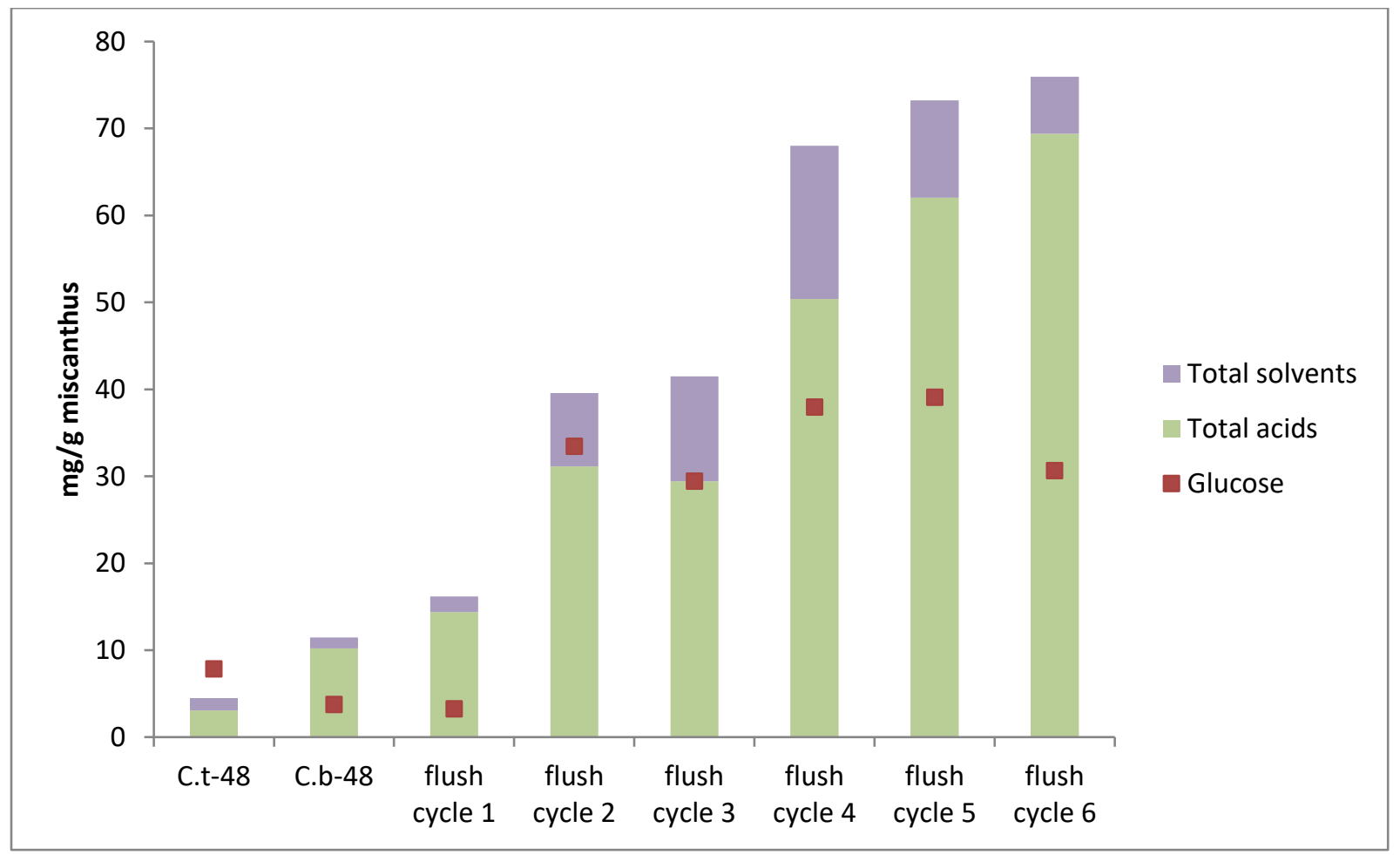


Figure $2 \mathrm{~b}$ Cycling through solventogenic phase by repeated flush with $\mathrm{T}$ medium and glucose (refer to Table 1-Treatment 2b)

Table 2a The yields of total products after seven repeated flushes cycling through the solventogenic phase using corn stover

\begin{tabular}{|l|l|l|l|l|l|l|}
\hline Flush Treatment & $\begin{array}{l}\text { Acetic } \\
\text { acid }\end{array}$ & Lactic acid & Butyric acid & Butanol & Total acids & Total ABE \\
\hline Treatment 1a & 17.23 & 9.25 & 24.51 & 3.43 & 43.21 & 6.00 \\
\hline Treatment 2a & 113.20 & 41.62 & 76.95 & 55.54 & 231.77 & 58.32 \\
\hline Treatment 3a & 14.83 & 5.96 & 13.29 & 5.87 & 34.01 & 7.5 \\
\hline
\end{tabular}

Table $2 b$ The yields of total products after seven repeated cycles through the solventogenic phase using miscanthus as substrate.

\begin{tabular}{|l|l|l|l|l|l|l|}
\hline Flush Treatment & $\begin{array}{l}\text { Acetic } \\
\text { acid }\end{array}$ & Lactic acid & Butyric acid & Butanol & Total acids & Total ABE \\
\hline Treatment 1b & 17.71 & 7.23 & 19.89 & 3.11 & 39.04 & 5.42 \\
\hline Treatment 2b & 136.7 & 69.33 & 60.95 & 54.96 & 267.0 & 58.88 \\
\hline Treatment 3b & 14.03 & 5.19 & 19.36 & 1.75 & 38.58 & 3.75 \\
\hline
\end{tabular}

\subsection{Treatment 4-Cycling through cellulolytic (with re-inoculation of $C$. thermocellum) and the} solventogenic phase (with re-inoculation of $C$. beijerinckii)

In Treatment 4, both the cellulolytic phase and the solventogenic phase were cycled repeatedly. The cellulolytic phase was repeated by flushing with T medium and fresh inoculum of $C$. thermocellum and raising the culture temperature back to $65^{\circ} \mathrm{C}$ for 48 hours prior to the solventogenic phase. Glucose concentrations accumulated to 4.5-5.5 g/L (18-22 mg/g dry substrate) when the column reactor was re-incubated at $65^{\circ} \mathrm{C}$ for $48 \mathrm{~h}$ using corn stover as the substrate (Figure 4a). Re-incubation of $C$. thermocellum in the column reactor using miscanthus generated 4.1-4.5 g/L glucose (16-18 mg/g) (Figure 4b). Cycling back through the cellulolytic phase increased the availability of glucose by at least 6-fold over the remaining sugars after 
solventogenesis. In addition, metabolites continued to accumulate after each recycle of cellulolytic and solventogenic phases (Figure $4 a$ and $4 b$ ). In the column reactor using corn stover, up to $88.1 \mathrm{mg} / \mathrm{g}$ of acids and $24.9 \mathrm{mg} / \mathrm{g}$ of solvents were obtained after 7 cycles of solventogenic phase (Table 3a), which was approximately 2 -fold and 4.1-fold higher than the accumuated acids and solvents from Treatment 1. In the column reactor using miscanthus, up to $73.5 \mathrm{mg} / \mathrm{g}$ of acids and $16.3 \mathrm{mg} / \mathrm{g}$ solvents were accumulated after the 7 solventogenic cycles (Table 3b), which was 1.9-fold and 3-fold over that from Treatment 1.

The above results showed that the cycling through the cellulolytic and solventogenic phases using fungal-pretreated biomass in this study improved the lignocellulosic conversion into metabolites in SSC. The biomass (corn stover or miscanthus) in the column reactor was pretreated with white rot fungus prior to inoculating with the Clostridium strains. Total lignin decreased by $25 \%-27 \%$ which improved the hydrolysis by $C$. thermocellum thereafter(Yao \& Nokes, 2014). Some researchers have stated that the remaining insoluble lignin after pretreatment didnot interfere with growth or hydrolysis when $C$. thermocellum cells were cultivated at optimum growth temperature of $65^{\circ} \mathrm{C}$ (Demain et al., 2005; Lynd \& Grethlein, 1987). The extracellular cellulase complex (cellulosome) of the cells has been shown to completely solubilize either crystalline substrate Avicel or pretreated lignocellulosic substrate, such as dilute-acid-pretreated mixed hardwoods. However, less than $8 \%$ of the cellulose in the lignocellulosic biomass could be degraded by $C$. thermocellum in a high solids batch cultivation due to the loss of cell volume Constant removal of metabolites, particularly the acids in the solid/high solids cultivation avoided the osmotic stress on the microorganism (Dharmagadda et al., 2010; Yao \& Nokes, 2014). The results from Treatment 4 verified that re-incubation of $C$. thermocellum by adding fresh medium with re-inoculum can provide consistently accessible carbohydrates for $C$. beijerinckii, because this treatement increased the availability of glucose by more than 6 fold over no reinoculation.

\subsection{Treatment 5 - Cycling through the cellulolytic phase (with no additional inoculum of $C$. thermocellum) and the solventogenic phase (with reinoculation of $C$. beijerinckii)}

Re-incubation (but not re-inoculation) of the existing $C$. thermocellum in the column reactor at $65^{\circ} \mathrm{C}$ increased the availability of glucose by at least 6 fold over the sugars remaining after 
solventogenesis (culture temperature at $35 \mathrm{C}$ ) even where no additional $C$. thermocellum inoculum was provided. The yields of total acids (lactic acid and acetic acid) and solvents (ethanol) from the cellulolytic phase were up to 7-14.6 mg/g and 2-3 mg/g (Figure 5a). Similar fermentation profiles have been obtained using miscanthus, however with slightly lower yields of acids and solvents after each cellulolytic phase (7-12.2 mg/g acids and 1.5-2.5 mg/g solvents) (Figure 5b). This observation indicates that the initial inoculum of $C$. thermocellum in the column reactor is viable throughout sequential co- culture at $35^{\circ} \mathrm{C}$ and was sufficiently active to hydrolyze cellulose and accumulate fermentation products when the column temperature was raised to $65^{\circ} \mathrm{C}$. We know the cellulolytic enzyme system functioned throughout the reincubation at $65^{\circ} \mathrm{C}$ because glucose accumulated from $0.7-1.4 \mathrm{~g} / \mathrm{L}$ to approximatly $4-5 \mathrm{~g} / \mathrm{L}$ after each cycle of cellulolytic stage. In addition, a $10 \times 1.5 \mathrm{~cm}$ filter paper strip was completely degraded within 2 days at $65^{\circ} \mathrm{C}$ by a culture of $C$. thermocellum collected from the column reactor after a solventogenic cycle (data not shown). This result further verified the cell viability and the activity of enzyme complex of $C$. thermocellum throughout the process.

After 7 repeated flushing cycles of the sequential co-culture, treatments 4 and 5 exhibited insignificant differences in yields of total acids and total solvents (Table 2). The results demonstrated that regular flushing of T media in high solids substrate cultivations improved cellulose conversion when compared to batch cultures reported by our previous study (Yao \& Nokes, 2014), however re-inoculation of $C$. thermocellum did not further improve the yields.

It is noteworthy that $C$. thermocellum was viable throughout sequential co- culture and actively fermented cellulose when re-incubated for up to 7 cycles (28 days) without apparent degeneration of the cells. In addition, the sequential co-culture produced a significant amount of endogenous gas which sufficiently maintained anaerobic conditions for further repeated flushing cycles. No further flushing of inert gas was employed (Figure 3).

In treatments 4 and 5, C. thermocellum produced acetic acid in addition to cellulose hydrolysis but the re-assimilation of acids to solvents by $C$. beijerinckii was not improved. Typically, it is believed that acids are produced in the first stage (acidogenic phase) and then re-assimilated as 
a co-substrate together with glucose for solvent production (solventogenic phase) (Al-Shorgani et al., 2012). Besides cellulolytic performance, another expected benefit to the use $C$. thermocellum prior to solventogenesis was the accumulation of acetic acid (4-8 mg/g or $25-40$ $\mathrm{mM})$. The $\mathrm{pH}$ throughout the flushing process was maintained between 6.0 and 6.5 within which the acetic acids are in the form of acetate. Investigations have demonstrated the positive effect of acetate in improving solvent production by up-regulating the enzymes involved in acidogenesis and solventogenesis. Chen (1999) increased the total solvent concentration for $C$. beijerinckii BA101 and NCIMB 8052 by 3.4-fold and 2.7-fold respectively for a culture grown in MP2 medium containing $80 \mathrm{mM}$ sodium acetate in $50 \mathrm{ml}$ batch. The increased solvent yields can be attributed to the increased expression of key enzymes (CoA transferase and aldehyde hydrogenase) associated with acid reassimilation and butanol production in solventogenic clostridia.

In our study, however, the increased levels of acetate and glucose produced during the cellulolytic phase did not enhance the solvent production by $C$. beijerinckii as the yield of butanol per g glucose was much lower than in liquid culture. The butanol yield from glucose by C. beijerinckii was $0.3 \mathrm{~g} / \mathrm{g}$ when the initial glucose concentration was between 30-60 g/L. In Treatment 1, little butanol was accumulated $(<0.05 \mathrm{~g} / \mathrm{L})$ in the sequential co-culture when the residual glucose level was $\ll 0.7 \mathrm{~g} / \mathrm{L}$. In the sequential co-culture effluent collected from treatments 4 and 5 , the glucose after the cellulolytic phase was increased to $4-5 \mathrm{~g} / \mathrm{L}$ and the butanol yield was round 0.06-0.15 g per g glucose, which was higher than he butanol concentration in treatment 1 , but still lower than the butanol yield $(0.3 \mathrm{~g} / \mathrm{g}$ glucose) from liquid culture . In treatments 1, 4 and 5, the butyrate yield over glucose was up to yield per gram of glucose was 2 5-fold higher than the butanol yield per g glucoce, indicating that the dominant metabolic mechanism at this stage was acidogenesis.

There are two main reasons that fermentations remain in the acidogenic state: (1) low sugar concentrations result in slow growth and the slow growth requires higher acids concentration for re-assimilation and (2) slow growth also leads to a slower transition for an acid to a solvent fermentation. Re-assimilation of acids to butanol required as high as $6.5 \mathrm{~g} / \mathrm{L}$ of acetic acid and 
$7.5 \mathrm{~g} / \mathrm{L}$ of butyric acid under a slow rate of metabolism. At a high rate of metabolism, acetic and butyric acids were re-assimilated at concentrations of $4.5 \mathrm{~g} / \mathrm{L}$ (Fond et al., 1985). Given a certain critical acid concentration in the fed-batch cultivation, the metabolic transition from acetogenesis to solventogenesis remained extremely slow when the sugar uptake rate which reflects the cell growth rate was below a value of $0.15 \mathrm{~h}^{-1}$. Above $0.25 \mathrm{~h}^{-1}$, on the contrary, the transition rate was sufficiently rapid to limit the formation of the inhibitory acids, and significant quantities of solvents can be produced during the second fermentation phase (Fond et al., 1986; Fond et al., 1985). It also has been found that the rate of acid re-assimilation by $C$. beijerinckii and C. acetobutylicum decreases once the concentration of substrate dropped below the threshold value required to sustain $A B E$ production in the reactor (Bahl \& Gottschalk, 1984; Ezeji et al., 2007; Rogers, 1986). These findings mean that a high critical level of acid has to be reached to initiate re-assimilation and an inefficient metabolic transition from an acid to a solvent fermentation will occur during a low growth rate. In the flushing column reactor developed in this study, the sugar concentration was insufficient to sustain efficient $A B E$ production, even though cycling through the cellulolytic phase improved the glucose availability. It is possible that some cells remained in the acidogenic phase throughout $A B E$ fermentation, and produced butyrate under low carbohydrate concentrations, thus resulting in acids accumulating in the column reactor.

These results may be explained on the basis of cellular energetics. The acidogenic phase liberates more ATP than the solventogenic phase. Moreover, both acetate and butyrate reassimilation require additional energy expenditure for the cell so the switch from acid production to acid re-assimilation may cause the loss in total energy (Amador-Noguez et al., 2011; Fond et al., 1986). When the substrate concentration is insufficient, the cellular metabolism is energetically limited by the low substrate utilization rate, thus leading to a slow growth rate. Under these conditions, the cell activity is preferentially oriented towards the production of acids to obtain the maximum energy (Fig. 6). Thus, availability of excess sugar in the column bioreactor is essential for both the onset (assimilation of acids) and the maintenance of solvent $(\mathrm{ABE})$ production. Cycling through the $C$. thermocellum phase can increase the glucose availability which resulted in higher yields of acids and solvents then when 
the $C$. thermocellum phase was not repeated. It will be necessary to further improve the cellulose conversion under high solids conditions to obtain a higher percent biomass conversion extent and rate if this process is to be commercially viable.
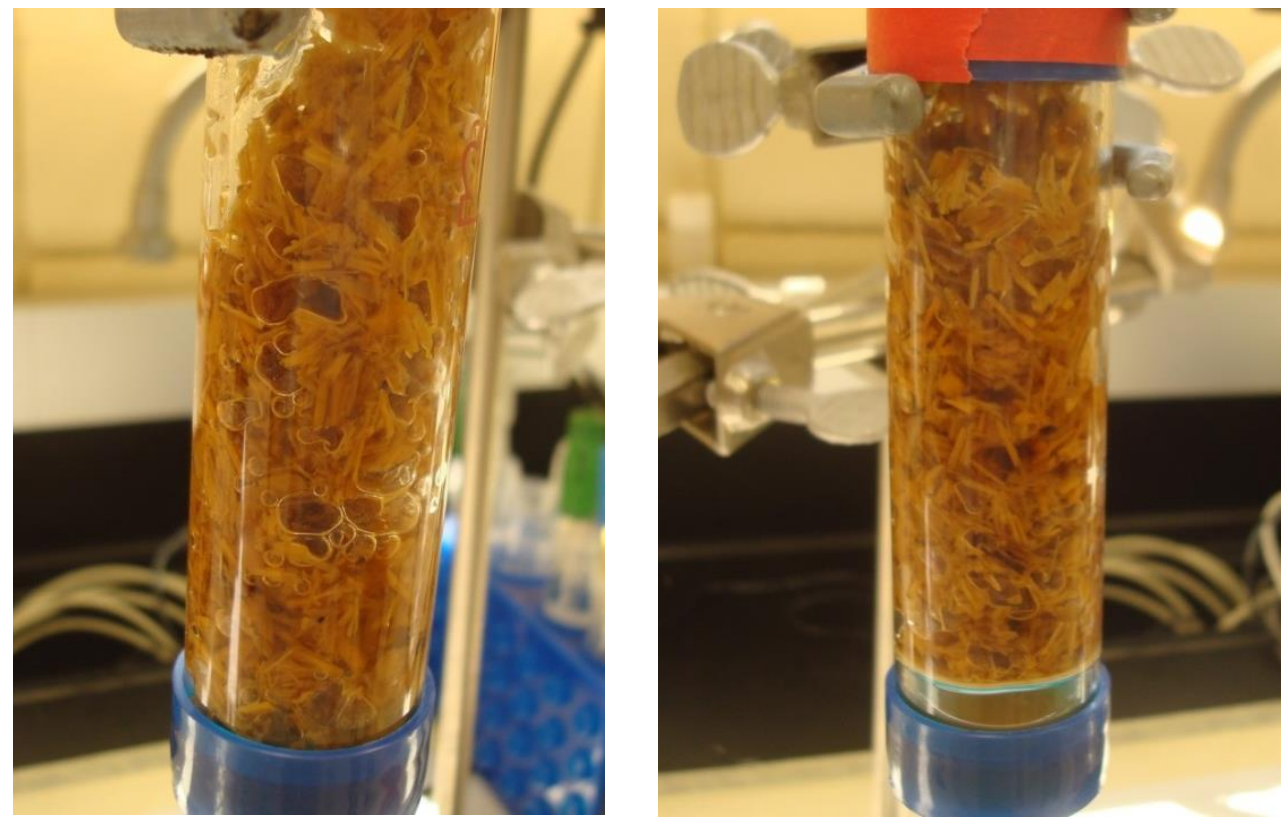

Figure 3. Column reactors which were cycled through cellulolytic and solventogenic phases. Endogenous gas was produced by sequential co-culture of $C$. thermocellum and $C$. beijerinckii, and this can be observed from the bubbles existing in the cultivation using corn stover (left); the accumulated endogenous gas increased the inner pressure sufficiently to push the miscanthus column up (right). 


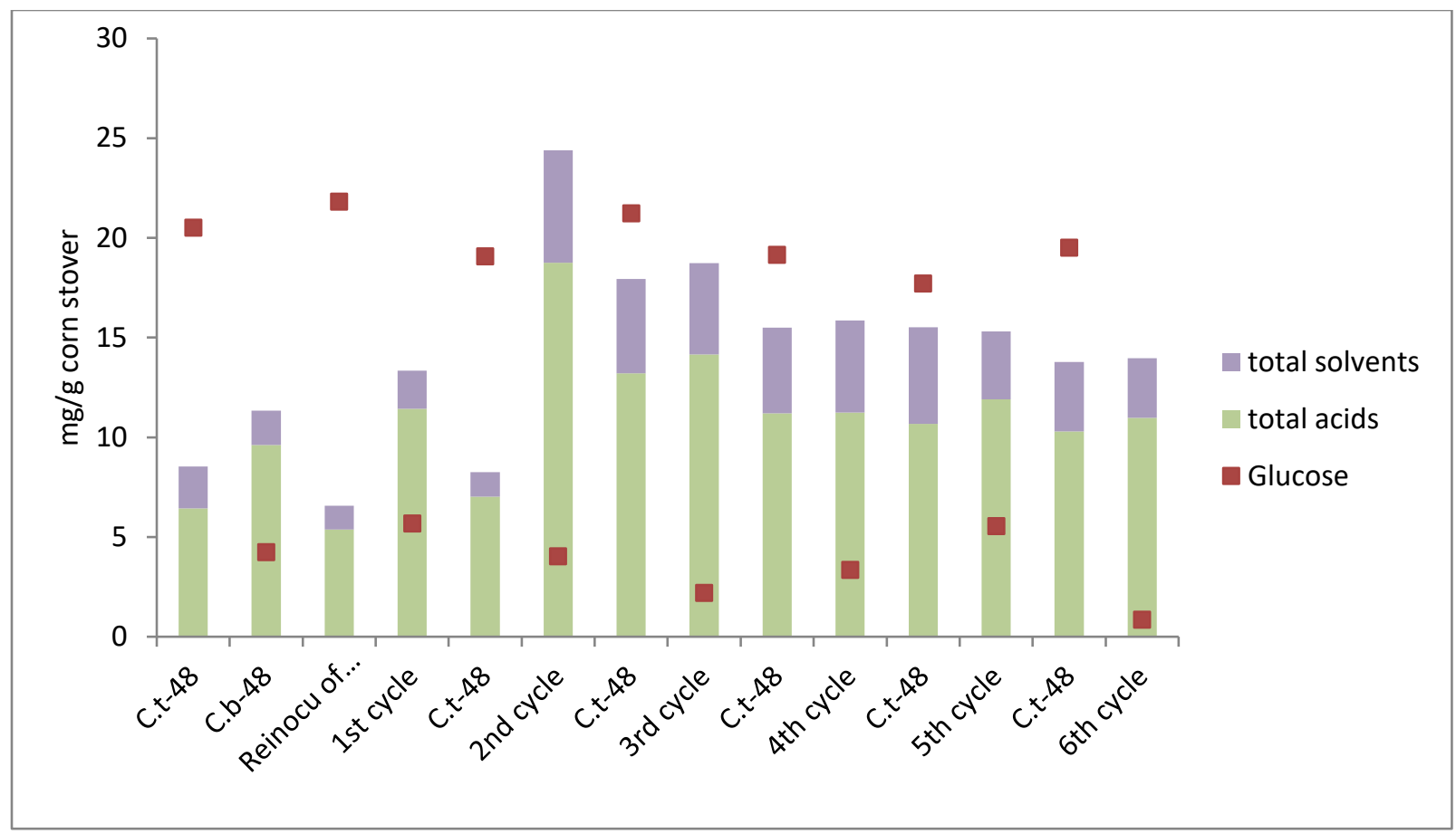

Figure 4a. Cycling through cellulolytic and solventogenic phases by repeatedly flushing with T-medium, reinoculated with $C$. beijerinckii using corn stover as the substrate (refer to Table 1-Treatment 4a).

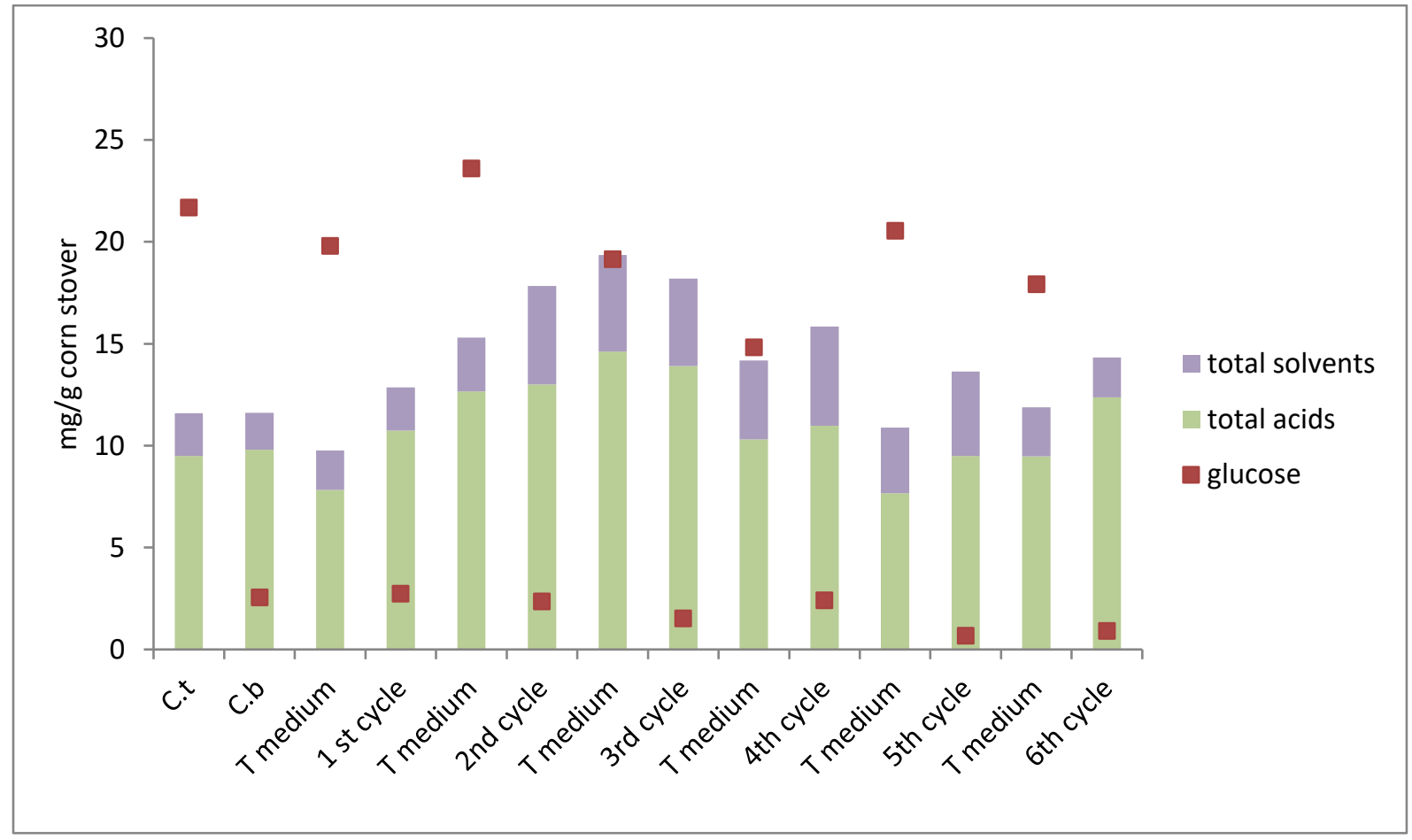

Figure 5a. Cycling through cellulolytic and solventogenic phases by repeatedly flushing with T-medium and $C$. thermocellum using corn stover as the substrate (refer to Table 1-Treatment 5a). 


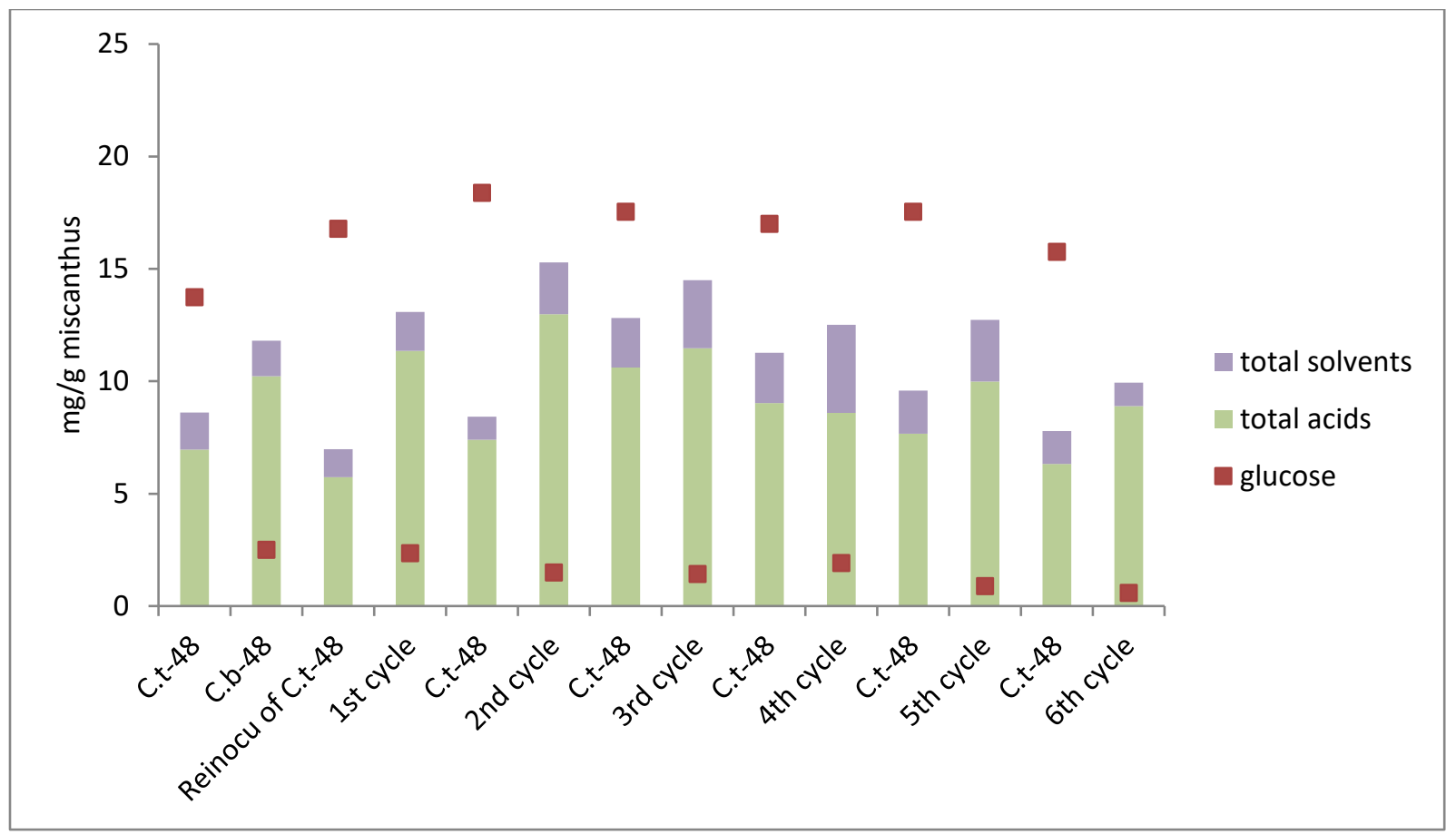

Figure 4b. Cycling through cellulolytic and solventogenic phases by repeatedlt flushing with T-medium using miscanthus as the substrate (refer to Table 1-Treatment 4b).

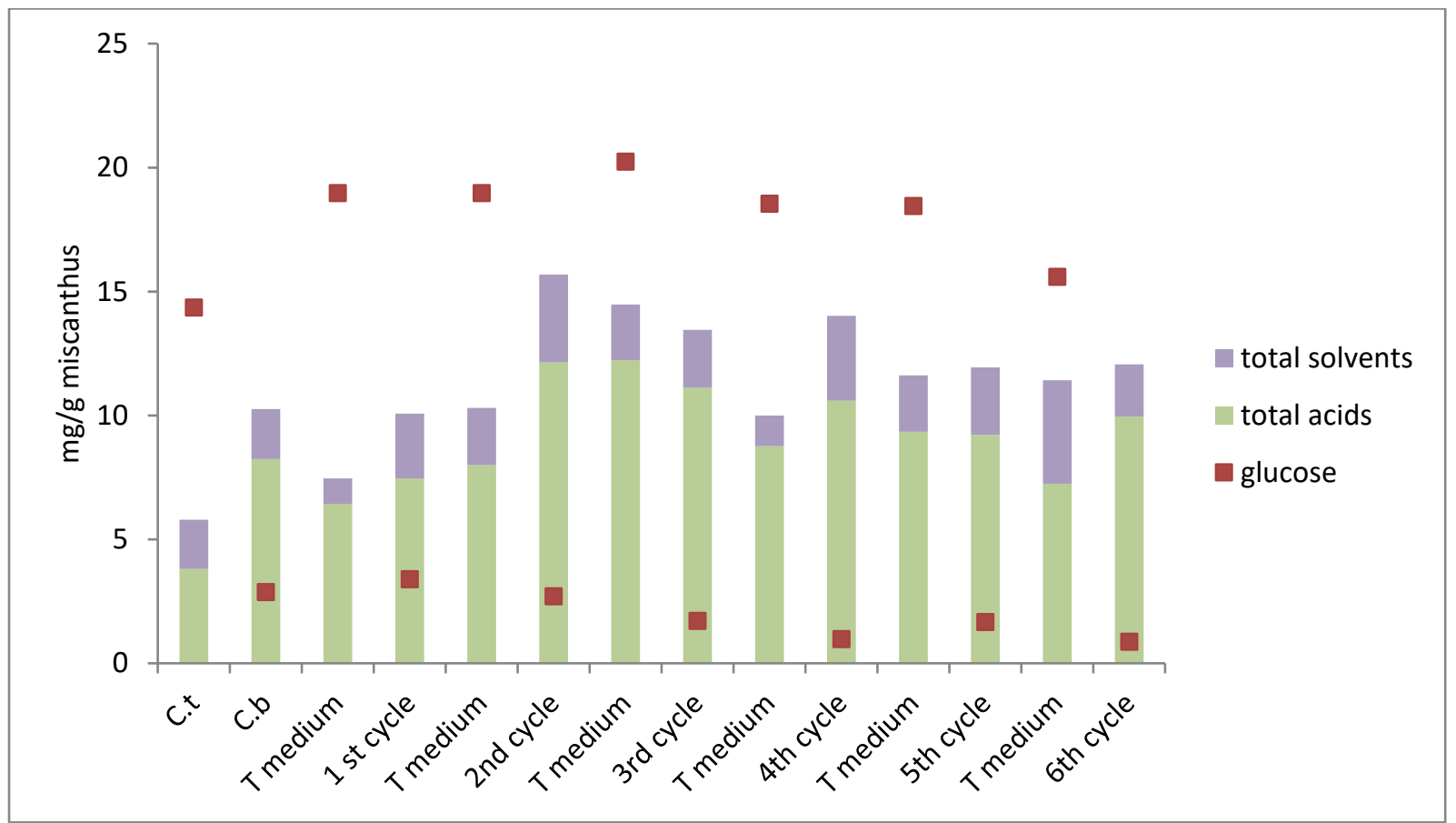

Figure 5b. Cycling through the cellulolytic and solventogenic phases by repeatedly flushing with Tmedium using miscanthus as the substrate (refer to Table 1-Treatment $5 b$ ). 


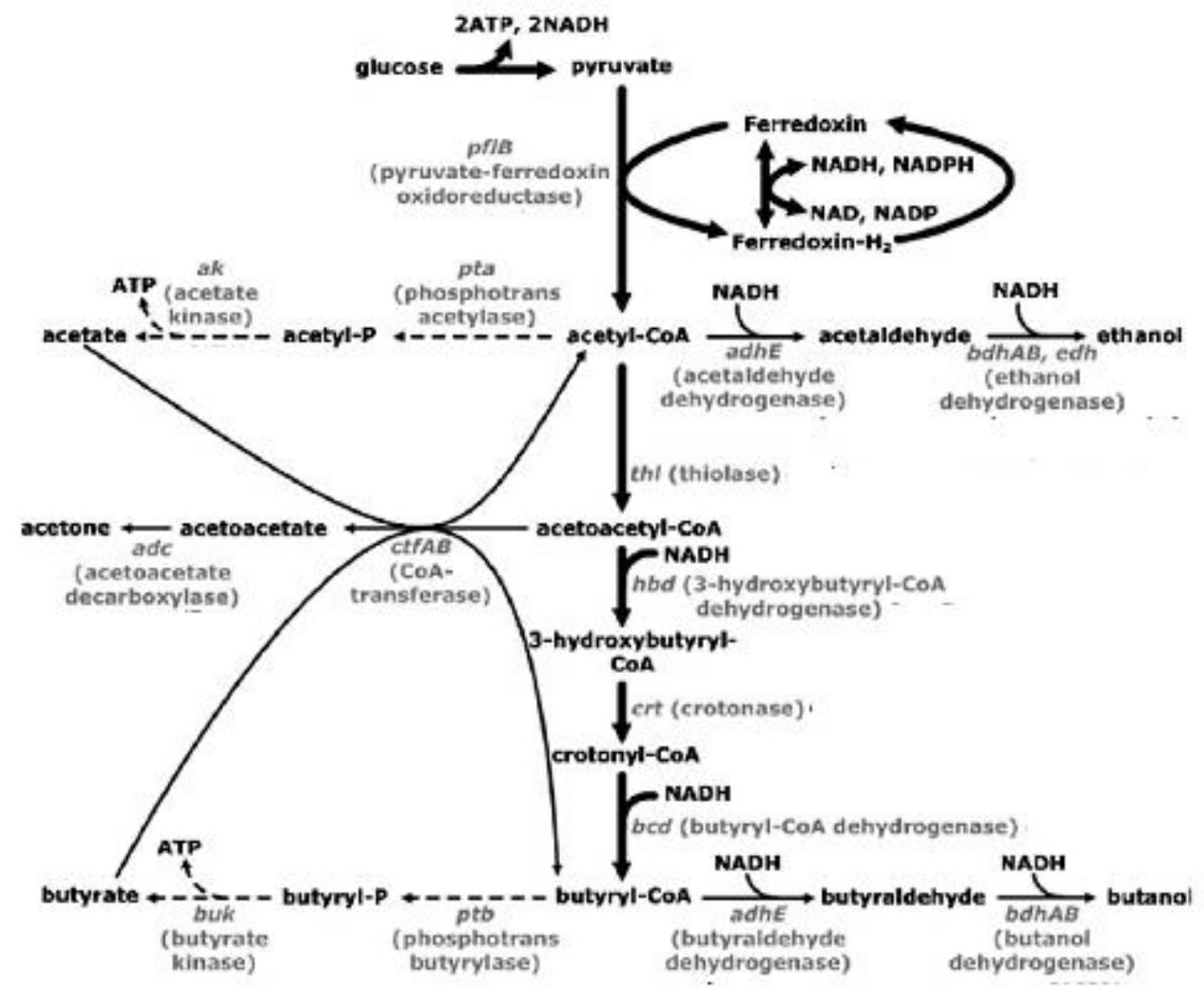

Figure 6 Metabolic pathways in C. beijerinckii. Dominate reactions in acidogenesis and solventogenesis are labeled in dotted and solid arrows, respectively. The schematic picture was modified after

Table 3a Final yields of products after cycling through cellulolytic phase using corn stover

\begin{tabular}{|l|l|l|l|l|l|l|}
\hline Total product $(\mathrm{mg} / \mathrm{g})$ & & & & & & \\
Flush process & Acetic acid & Lactic acid & Butyric acid & Butanol & Total acids & Total ABE \\
\hline Treatment 4a & 32.76 & 3.80 & 51.51 & 12.24 & 88.08 & 24.86 \\
\hline Treatment 5a & 33.34 & 4.38 & 42.58 & 14.36 & 80.30 & 24.00 \\
\hline
\end{tabular}


Table 3b Final yields of products after cycling through cellulolytic phase using miscanthus

\begin{tabular}{|l|l|l|l|l|l|l|}
\hline $\begin{array}{r}\text { Total product }(\underline{\mathrm{mg} / \mathrm{g}}) \\
\text { Flush process }\end{array}$ & Acetic acid & Lactic acid & Butyric acid & Butanol & Total acids & Total ABE \\
\hline Treatment $4 \mathrm{~b}$ & 29.21 & 2.70 & 7.44 & 9.63 & 73.53 & 16.34 \\
\hline Treatment 5b & 31.35 & 2.96 & 34.41 & 9.64 & 68.72 & 18.75 \\
\hline
\end{tabular}

\section{Conclusions}

Examination of the sustainability of the cycling system throughout the cellulolytic and solventogenic phases using high solids fermentation of lignocellulosic biomass was performed in this study. It was found that sustainable metabolite accumulation by regular flushing through the solventogenic phase was not feasible due to the limited glucose concentration made available from the biomass hydrolysis by $C$. thermocellum in the high solids batch cultivation. The cellolytic enzyme system of $C$. thermocellum appears to be the limiting step in the coculture. The rate of the enzymatic hydrolysis is highly dependent on culture temperature. This study confirms the necessity of re-incubating the column at $65{ }^{\circ} \mathrm{C}$ to produce additional enzymes to hydrolyze the cellulose into glucose in the flushing system. Cycling through the cellulolytic phase with or without re-inoculation of $C$. thermocellum improved glucose availability for the following solventogenic phase thus increasing the total acids and solvents accumulation. These findings indicated that the initial inoculum of $C$. thermocellum remained viable throughout sequential co- culture. Additionally, process simplicity can be achieved by re-incubating the flushed cellulolytic phase with no re-inoculation. Therefore, in order to improve biomass conversion in high solids fermentation, flushing on regular intervals throughout the cellulolytic and solventogenic phases is suggested. In a future study, process optimization and hydrolysis kinetic will be investigated to further improve products yields.

\section{Acknowledgement}

The authors sincerely acknowledge the financial support of the United States Department of Agriculture National Institute for Food and Agriculture Biomass Research and Development 
Initiative Grant \# 2011-10006-30363. The investigation reported in this paper (No. 14-05-055) is a part of a project of the Kentucky Agricultural Experiment Station and is published with the approval of the director. We are also eternally grateful to the staff member Manish Kulshrestha for his technical support.

\section{References}

Al-Shorgani, N.K.N., Ali, E., Kalil, M.S., Yusoff, W.M.W. Bioconversion of Butyric Acid to Butanol by Clostridium saccharoperbutylacetonicum N1-4 (ATCC 13564) in a Limited Nutrient Medium. Bioenergy Research,2012. 5(2), 287-293.

Amador-Noguez, D., Brasg, I.A., Feng, X.J., Roquet, N., Rabinowitz, J.D. Metabolome Remodeling During the Acidogenic-Solventogenic Transition in Clostridium acetobutylicum. Applied and Environmental Microbiology,2011. 77(22), 7984-7997.

Bahl, H., Gottschalk, G. Parameters Affecting Solvent Production by Clostridium acetobutylicum in Continuous Culture. Biotechnology and Bioengineering,1984. 215-223.

Chen, C.K., Blaschek, H.P. Acetate Enhances Solvent Production and Prevents Degeneration in Clostridium beijerinckii Ba101. Applied Microbiology and Biotechnology,1999. 52(2), 170-173.

Chen, W.H., Chen, Y.C., Lin, J.G. Evaluation of Biobutanol Production from Non-Pretreated Rice Straw Hydrolysate under Non-Sterile Environmental Conditions. Bioresource Technology,2013. 135, 262-268.

Clark, J.H., Luque, R., Matharu, A.S. Green Chemistry, Biofuels, and Biorefinery. Annual Review of Chemical and Biomolecular Engineering,2012. 3, 183-207.

Cotta, M.A., Russell, J.B. Effect of Peptides and Amino-Acids on Efficiency of Rumen Bacterial ProteinSynthesis in Continuous Culture. Journal of Dairy Science,1982. 65(2), 226-234.

Demain, A.L., Newcomb, M., Wu, J.H.D. Cellulase, Clostridia, and Ethanol. Microbiology and Molecular Biology Reviews,2005. 69(1), 124-+.

Dharmagadda, V.S., Nokes, S.E., Strobel, H.J., Flythe, M.D. Investigation of the Metabolic Inhibition Observed in Solid-Substrate Cultivation of Clostridium thermocellum on Cellulose. Bioresource Technology,2010. 101(15), 6039-6044.

Ezeji, T., Qureshi, N., Blaschek, H.P. Production of Acetone-Butanol-Ethanol (Abe) in a Continuous Flow Bioreactor Using Degermed Corn and Clostridium beijerinckii. Process Biochemistry,2007. 42(1), 34-39.

Fond, O., Engasser, J.M., Mattaelamouri, G., Petitdemange, H. The Acetone Butanol Fermentation on Glucose and Xylose .2. Regulation and Kinetics in Fed-Batch Cultures. Biotechnology and Bioengineering,1986. 28(2), 167-175.

Fond, O., Mattaammouri, G., Petitdemange, H., Engasser, J.M. The Role of Acids on the Production of Acetone and Butanol by Clostridium acetobutylicum. Applied Microbiology and Biotechnology,1985. 22(3), 195-200.

Gervais, P., Molin, P. The Role of Water in Solid-State Fermentation. Biochemical Engineering Journal,2003. 13(2-3), 85-101.

Johnson, E., Reese, E., Demain, A. Inhibition of Clostridium thermocellum Cellulase by End Products of Cellulolysis. J. Appl. Biochem.,1982. 4, 64-71. 
Kristensen, J.B., Felby, C., Jorgensen, H. Yield-Determining Factors in High-Solids Enzymatic Hydrolysis of Lignocellulose. Biotechnology for Biofuels,2009. 2.

Kumar, P., Barrett, D.M., Delwiche, M.J., Stroeve, P. Methods for Pretreatment of Lignocellulosic Biomass for Efficient Hydrolysis and Biofuel Production. Industrial and Engineering Chemistry Research,2009. 48(8), 3713-3729.

Lynd, L.R., Grethlein, H.E. Hydrolysis of Dilute Acid Pretreated Mixed Hardwood and Purified Microcrystalline Cellulose by Cell-Free Broth from Clostridium thermocellum. Biotechnology and Bioengineering,1987. 29(1), 92-100.

Nigam, P.S., Singh, A. Production of Liquid Biofuels from Renewable Resources. Progress in Energy and Combustion Science,2011. 37(1), 52-68.

Qureshi, N., Blaschek, H.P. Abe Production from Corn: A Recent Economic Evaluation. Journal of Industrial Microbiology \& Biotechnology,2001. 27(5), 292-297.

Rogers, P. Genetics and Biochemistry of Clostridium Relevant to Development of Fermentation Processes. Advances in Applied Microbiology,1986. 31, 1-60.

Selig, M.J., Hsieh, C.W.C., Thygesen, L.G., Himmel, M.E., Felby, C., Decker, S.R. Considering Water Availability and the Effect of Solute Concentration on High Solids Saccharification of Lignocellulosic Biomass. Biotechnology Progress,2012. 28(6), 1478-1490.

Shi, J., Sharma-Shivappa, R.R., Chinn, M., Howell, N. Effect of Microbial Pretreatment on Enzymatic Hydrolysis and Fermentation of Cotton Stalks for Ethanol Production. Biomass and Bioenergy,2009. 33(1), 88-96.

Todd, W.G. 1972. Water Deficits and Enzymatic Activity. in: Plant Response and Control of Water Balance, (Ed.) T.T. Kozlowski, Vol. 3, pp. 117-216.

Yao, W.Y., Nokes, S.E. Phanerochaete chrysosporium Pretreatment of Biomass to Enhance Solvent Production in Subsequent Bacterial Solid-Substrate Cultivation. Biomass \& Bioenergy,2014. 62, 100-107. 